- Patient/parent recall of facts discussed during the consent process is generally good.

- Particular emphasis should be placed on risks of orthodontic treatment at the time of consent.

- Consent should be considered an on-going process.

\title{
Consent to orthodontic treatment - is it working?
}

\author{
S. Ernst, ${ }_{1}^{1}$ T. Elliot, ${ }^{2}$ A. Patel, ${ }^{3}$ D. Sigalas ${ }_{1}^{4}$ H. Llandro, ${ }^{5}$ J. R. Sandy and A. J. Ireland ${ }^{7}$
}

\begin{abstract}
Objective To determine the level of patient and/or parent recall of previous consent to orthodontic treatment.

Design Patients and/or parents of children who had been consented for orthodontic treatment were asked to complete a questionnaire on consent at least six months into their treatment.
\end{abstract}

\section{Setting Bristol Dental Hospital.}

Subjects and methods Forty-one consecutive patients and eight of their parents, with a combined age range of 12-59 years, with 61\% being female and 39\% male. The patients, and where applicable their parents, were identified as having previously signed a consent form at least six months previously. Each was asked to complete a questionnaire on aspects of the consent process.

Results Patients and parents demonstrated a high level of recall for the consent process concerning appliance type (89.8\%), the reasons for treatment (96\%), risks (75.5\%), length of treatment (83.3\%), the opportunity to ask questions (96\%), and whether other information was provided (94\%). However, further questioning on risks demonstrated poor recall for important factors such as decay (36.8\%), root resorption (less than 21\%), retention (56.3\%) and length of retention (35\%).

Conclusions Overall the consent process works well but specific areas of concern centre around the risks of orthodontic treatment.

\section{INTRODUCTION}

It is implicit that dentists treat patients with respect and act in their best interests. ${ }^{1}$ Despite fixed professional opinion of what might constitute optimal treatment, patients must be informed of the various treatment options available to manage their clinical problem. They must be given sufficient information

\footnotetext{
'General Dental Practitioner, Clevedon, Somerset, BS21 6EW; ${ }^{2}$ General Dental Practitioner, Wareham, Dorset, BH20 5PO; ${ }^{3}$ General Dental Practitioner, Mill Hill, London, NW7 40E; ${ }^{4}$ General Dental Practitioner, Penylan, Cardiff, CF23 5AF; ${ }^{5}$ General Dental Practitioner, New Malden, Surrey, KT3 4HS; ${ }^{6}$ Professor of Orthodontics, ${ }^{7 *}$ Senior Lecturer/Honorary Consultant in Orthodontics, Child Dental Health, Bristol Dental Hospital and School, Lower Maudlin Street, Bristol, BS1 2LY

*Correspondence to: Dr Tony Ireland

Email: tony.ireland@bristol.ac.uk
}

\section{Online article number E25}

Refereed Paper - accepted 15 November 2006

DOI: $10.1038 /$ bdj.2007.329

${ }^{\circledR}$ British Dental Journal 2007; 202: E25 to be able to make an informed choice and must also have the capacity to understand the information presented to them during the consent process. ${ }^{2}$ If a patient has not consented to any proposed investigations or treatment, any clinical activity can leave the practitioner open to allegations of negligence, and less likely battery, for which damages are liable. ${ }^{3}$ By gaining consent, the dentist is deemed to have the licence to commit what would otherwise be considered an unlawful act. ${ }^{4}$ This position is embedded within the General Dental Council document Principles of patient consent ${ }^{1}$ where it is stated that 'It is a general legal and ethical principle that you must get valid consent before starting treatment or physical investigation, or providing personal care, for a patient. This principle reflects the right of patients to decide what happens to their own bodies, and is an essential part of good practice.' The precise definition of consent and indeed valid consent presents difficulties, but in general for consent to be valid certain assumptions are required and these include:

- The patient must be given sufficient information to make an informed decision

- They must not be pressured or coerced into accepting the treatment

- The person providing the information has sufficient knowledge to explain the procedure, including the risks and alternative treatment options

- Consent should be seen as an on-going process and not a one-off event

- Once a patient has given their consent they may withdraw it at any time.

As a result of the Bristol Royal Infirmary ${ }^{5}$ and Alder Hey inquiries, ${ }^{6}$ the Department of Health published a reference guide to consent for examination or treatment ${ }^{7}$ together with generic consent forms for use in differrent situations. Which form is used depends upon the procedure to be undertaken and the ability of the patient to consent to their own treatment. Interestingly, some three years after its introduction, clinicians did not always understand the process of consent and when it should be applied. ${ }^{8}$ Certain aspects of the new consent 


\section{Table 1 The consent questionnaire}

1. Do you (or your parents) remember signing a consent form before you started your brace treatment?

2. Did you know the name of the person who explained the consent form to you?

3. Were you told that the treatment might be carried out by someone other than the person who went through the consent form with you?

4. Were you told what type of brace you would have?

5. Were you told about any teeth that needed to be taken out as part of the treatment?

6. Were you offered any alternative types of treatment?

7. Was it explained to you why you were having the brace treatment?

8. If the answer to question 7 was Yes, what were the reasons?

i) Straight teeth (aesthetics)

ii) Improved function (bite)

iii) Improved health (easier to clean the teeth)

9. Were you informed of the serious or frequently occurring risks of treatment?

10. Which of the following risks were you told about?

i) Decay (caries)

ii) Painful teeth

iii) Trauma (rubbing from the brace)

iv) Root resorption (shortening of the tooth roots)

11. Were you told how long the treatment would take?

12. If you were told how long the treatment would take, can you remember what you were told in months or years?

13. Were you given the chance to ask any questions about the treatment?

14. Once the consent form was signed were you told you could still change your mind about the treatment at anytime?

15. Were you given any other information to take away with you?

16. If you were given extra information, which of the following was it?

i) Leaflets

ii) Videos

iii) Other

17. Were you told about retainers?

18. Were you told how long you would have to wear the retainers?

19. Were you given a copy of the consent form?

20. If you did get a copy of the consent form, what did you do with it?

procedures and forms have been shown to improve the process. For example, patients are provided with a greater explanation of any proposed procedure and possible resulting complications. However, in other respects matters have not improved. Commonly, the explanation of alternative treatment options is not always provided. ${ }^{9}$ Certainly it is known that the act of signing a consent form does not guarantee patient understanding of a proposed procedure and alone does not therefore constitute valid consent. ${ }^{10,11}$ Consent must therefore be considered a process of which signing the form is only one part. There is evidence that understanding, and by inference validity, is improved with the use of appropriate and well written patient information literature. ${ }^{12,13}$
The aim of this investigation was to determine recall of the consent process by patients and their parents undergoing routine orthodontic treatment at Bristol Dental Hospital.

\section{SUBJECTS AND METHODS}

Forty-one consecutive patients and eight parents of patients undergoing active orthodontic treatment, and where a copy of the Department of Health consent form 3 could be identified in the notes, were asked to participate in this study. It was also determined that participants, in addition to being given verbal information on the treatment, its benefits and risks, had been given one of the British Orthodontic Society patient information leaflets prior to commencing the proposed treatment. Local research ethics committee approval was granted for the patients, and where applicable their parents, to be asked to complete a questionnaire on their previous history of consent to orthodontic treatment at the dental hospital (REC reference number 04/Q2001/132). The questionnaire comprised 20 questions (Table 1). Each patient was approached to complete the questionnaire whilst attending the Dental Hospital for their routine orthodontic treatment and each was identified as being at least six months into treatment. The patient, and/or parent, was asked to answer each question in turn. Most questions were closed, requiring 'yes' or 'no' answers. However, some questions were used to determine whether they could recall why they were to wear a brace, what the risks were, how long the treatment would take (experience tends to show that this is a question which many patients repeatedly ask at subsequent visits to their orthodontist), whether they received additional sources of information during the consent process and finally if they could remember what subsequently happened to their copy of the signed and completed consent form.

\section{RESULTS}

The age range of the respondents was 12-59 years with 61\% being female and 39\% male.

The results of the closed questions are shown as percentage responses in Table 2. The results of the open questions are provided in Table 3. Encouragingly, most patients and their parents (over 80\%) remember signing a consent form prior to commencing their orthodontic treatment. Worryingly, fewer than 50\% could remember who had explained the process and obtained the consent, even though in many cases it would have been the operator who subsequently performed their treatment. This does, however, appear to correlate with the fact that they were told the treatment might be carried out by someone other than the person performing the treatment, as can often occur in a Dental Hospital and School. There were also a high percentage of positive answers to the questions on which type of appliance was to be used (89.8\%), why the orthodontic treatment was being performed (96\%), on risks (75.5\%), the length of treatment (83.3\%), the opportunity to ask questions $(96 \%)$ and whether other information was provided (94\%). In the latter case, $100 \%$ could remember being provided with an information leaflet (Table 3). On the question of extractions, $77.1 \%$ could recall being told about the need for extractions and approximately 73\% of the cases were extraction cases.

Perhaps less reassuring were the responses to the questions on risk and retention. Only $36.8 \%$ recall being told about decay and less than $21 \%$ could recall being informed about the risks 
Table 2 Percentage yes/no responses to each of the closed questions

\begin{tabular}{|l|l|l|l}
\hline \multicolumn{2}{|l|}{ Question } & Yes & No \\
\hline 1 & Do you (or your parents) remember signing a consent form before you started your brace treatment? & $81.6 \%$ & $18.4 \%$ \\
\hline 2 & Did you know the name of the person who explained the consent form to you? & $44.9 \%$ & $55.1 \%$ \\
\hline 3 & $\begin{array}{l}\text { Were you told that the treatment might be carried out by someone other than the person who went through the } \\
\text { consent form with you? }\end{array}$ & $56.3 \%$ & $43.7 \%$ \\
\hline 4 & Were you told what type of brace you would have? & $89.8 \%$ & $10.2 \%$ \\
\hline 5 & Were you told about any teeth that needed to be taken out as part of the treatment? & $77.1 \%$ & $22.9 \%$ \\
\hline 6 & Were you offered any alternative types of treatment? & $14 \%$ & $86 \%$ \\
\hline 7 & Was it explained to you why you were having the brace treatment? & $96 \%$ & $4 \%$ \\
\hline 9 & Were you informed of the serious or frequently occurring risks of treatment? & $75.5 \%$ & $24.5 \%$ \\
\hline 11 & Were you told how long the treatment would take? & $83.3 \%$ & $16.7 \%$ \\
\hline 13 & Were you given the chance to ask any questions about the treatment? & $96 \%$ & $4 \%$ \\
\hline 14 & $\begin{array}{l}\text { Once the consent form was signed were you told you could still change your mind about the treatment } \\
\text { at anytime? }\end{array}$ & $65.3 \%$ & $34.7 \%$ \\
\hline 15 & Were you given any other information to take away with you? & $94 \%$ & $6 \%$ \\
\hline 17 & Were you told about retainers? & $56.3 \%$ & $43.7 \%$ \\
\hline 18 & Were you told how long you would have to wear the retainers? & $35 \%$ & $65 \%$ \\
\hline 19 & Were you given a copy of the consent form? & $62 \%$ & $38 \%$ \\
\hline
\end{tabular}

of root resorption. With regard to retention, only $56.3 \%$ of patients said they were told about retainers and only 35\% were told how long the retainers might have to be worn.

When asked whether they remembered being given a copy of their consent form and what they subsequently did with it, $62 \%$ said they were given a copy and only $38.8 \%$ could remember filing it.

\section{DISCUSSION}

In establishing informed consent, a patient or parent must be provided with sufficient information to enable them to decide whether or not to proceed with an investigation or treatment. The consequences of not obtaining such consent can leave the practitioner open to allegations of negligence and, much less often, battery. Aside from the medico-legal aspects of consent, it has been shown that patients who are well informed comply better with any proposed treatment or intervention, ${ }^{14}$ which is perhaps particularly important in orthodontics where progress is almost totally reliant on good patient co-operation. ${ }^{15}$ Certainly the current study demonstrates encouraging results for patient or parental recall of features in the consent process, such as appliance type (89.8\%), the need for extractions $(77.1 \%)$, the reasons for the orthodontic treatment (96\%), adverse risks (75.5\%), treatment length (83.3\%) and written information. This is particularly encouraging in that the cases were six or more months into treatment. A previous study has demonstrated 100\% recall for questions on the consent process, including information provided, risks, treatment time and commitment to treatment. However, what was unclear from this latter study was how soon after consenting the patient or parents were asked about the process. ${ }^{16}$ It could be argued that the present questionnaire should have been given just prior to commencement of treatment and not six months into treatment, since patients might be expected to know the answer to questions such as what appliance was being used, the length of the treatment and the need for extractions as treatment progresses. However, if consent is to be considered a process it can also be argued that during treatment, as procedures are repeatedly discussed with patients, then clinicians are making consent an ongoing process with the patient able to withdraw from treatment at any time.

Of particular concern when obtaining consent is that the patient or parent is fully informed of any significant risks that might affect their decision whether or not to proceed with a particular procedure. ${ }^{17}$ In the case of orthodontic treatment, pain, trauma, and in particular caries and root resorption ${ }^{18}$ are significant risks that patients should be aware of before making a decision. In adult patients, particularly with a history of periodontal disease, further risk to the periodontium should also be discussed. Precisely what risks should be discussed with a patient is poorly defined and often left to the judgement of the individual practitioner, although there is a now gradual shift from the Bolam ${ }^{19}$ standard of "what a reasonable practitioner would advise' towards 'what a reasonable patient would expect to hear'. In the present study, 75.5\% of patients or parents could recall being told about risks. However, two of the side effects or risks are irreversible, namely caries and root resorption, and only $36.8 \%$ and $20.4 \%$ of patients respectively, could recall having been told this six or more months previously. This is unfortunate, since it is known that up to $49.6 \%$ of patients may demonstrate evidence of decalcification on completion of orthodontic treatment ${ }^{20}$ and up to $40 \%$ might show evidence of macroscopic root resorption. ${ }^{21}$ Within the written information provided to all of the patients, the risk of caries was highlighted but root resorption was not and this may go someway towards explaining why the latter risk in particular was not well 
Table 3 Percentage responses to open questions 8, 10, 12, 16 and 20

\begin{tabular}{|c|c|c|}
\hline \multicolumn{2}{|c|}{ Question } & \multirow[b]{2}{*}{$\begin{array}{l}87.8 \% \\
38.8 \% \\
8.2 \%\end{array}$} \\
\hline 8 & $\begin{array}{l}\text { If the answer to question } 7 \text { (Was it explained to you } \\
\text { why you were having the brace treatment?) was Yes, } \\
\text { what were the reasons? } \\
\text { i) Straight teeth (aesthetics) } \\
\text { ii) Improved function (bite) } \\
\text { iii) Improved health (easier to clean the teeth) }\end{array}$ & \\
\hline 10 & $\begin{array}{l}\text { Which of the following risks were you told about? } \\
\text { i) Decay (caries) } \\
\text { ii) Painful teeth } \\
\text { iii) Trauma (rubbing from the brace) } \\
\text { iv) Root resorption (shortening of the tooth roots) }\end{array}$ & $\begin{array}{l}36.8 \% \\
57.1 \% \\
40.8 \% \\
20.4 \%\end{array}$ \\
\hline 12 & $\begin{array}{l}\text { If you were told how long the treatment would take, } \\
\text { can you remember what you were told in months } \\
\text { or years? }\end{array}$ & $\begin{array}{l}\text { Range 9-41 } \\
\text { months }\end{array}$ \\
\hline 16 & $\begin{array}{l}\text { If you were given extra information which of the } \\
\text { following was it: } \\
\text { i) Leaflets } \\
\text { ii) Videos } \\
\text { iii) Other }\end{array}$ & $\begin{array}{l}100 \% \\
2 \% \\
12.2 \%\end{array}$ \\
\hline 20 & $\begin{array}{l}\text { If you were given a copy of the consent form do you } \\
\text { remember what you did with it? } \\
\text { i) Filed } \\
\text { ii) Disposed } \\
\text { iii) No answer, unsure or lost }\end{array}$ & $\begin{array}{l}38.8 \% \\
2 \% \\
59.2 \%\end{array}$ \\
\hline
\end{tabular}

recalled. Certainly this lack of recall or awareness is in agreement with a previous study, which showed that up to $41 \%$ of parents were unaware of the possibility of decay associated with orthodontic appliances. ${ }^{22}$ Other risks that were poorly recalled by patients and parents were relapse and the need for retainers. Only 56.3\% of patients could recall being told about retention and fewer, only 35\%, could recall how long they would have to be worn following treatment. This poor recall of risk is in agreement with previous studies on consent in both orthodontics ${ }^{16}$ and other disciplines. ${ }^{23}$ It is therefore important that any risks which are discussed are specifically entered on the written consent, a copy of which should be kept in the patient's records and another copy given to the patient. However, the current study would suggest $60 \%$ of patients would not be able to locate their copy at a later date. This need to consider and accurately record all of the significant risks has been highlighted by the recent case of Chester vs Afshar. ${ }^{24}$ Here a patient was successful in a legal action against a practitioner, a neurosurgeon, who did not discuss the possibility of cauda equina syndrome following surgery, even though the incidence of this complication was low at only $1-2 \%$. It was considered that although the risk was low, the consequences to the patient of the risk occurring were significant and the patient may not have proceeded with the treatment if informed of this risk. It could be argued that the dental risks of orthodontic treatment outlined in the questionnaire in this study are also significant, and should be explained to the patient as part of informed consent, especially with headgear use where there is a risk of eye damage. ${ }^{25}$

In the present study, 100\% of patients and parents could recall being provided with a patient information leaflet and in each case this was one of the leaflets available from the
British Orthodontic Society. Well written information leaflets have been shown not only to reduce patient anxiety towards treatment, ${ }^{26}$ but also to improve recall of the risks involved. ${ }^{27}$ Although the leaflets provided in the present study did present the risks of orthodontic treatment, recall by patients and parents was still fairly poor. A newly available British Orthodontic Society leaflet, specifically dealing with risks, may prove to be more effective in the future. Certainly the use of written or visual information as well as verbal information has been shown to improve patient recall following a consultation. ${ }^{28}$

\section{CONCLUSIONS}

The results of the present study would indicate that in many respects the consent process worked well, with good patient and parent recall six or more months after the start of treatment. However, the areas of most concern were those which might lead a patient to choose not to undergo treatment, namely the risks of treatment and the need to wear retainers for a protracted period of time following completion of treatment. It would seem that more emphasis should be placed on these aspects of treatment if the consent process is to be considered valid. In addition, this study highlights the need to maintain comprehensive and contemporaneous records concerning the information provided during the consent process, in case the patient should wish to challenge this at a later date.

The authors wish to thank Dr Gordon Taylor, Senior Medical Statistician, Royal United Hospital Bath for his help with the questionnaire.

1. General Dental Council. Standards for dental professionals. London: General Dental Council, 2005.

2. Re C (adult: refusal of treatment) [1994] 1 W.L.R. 290, [1994] 1 All E.R. 819.

3. Schloendorff $\vee$ Society of New York Hospital, 1914. Court of Appeals New York, 211 NY 125 at 126, Lexis-Nexis.

4. Coreless-Smith D. Consent to treatment. In Lambden P (ed) Dental law and ethics. pp 74-75. Oxford: Radcliffe Medical Press, 2002.

5. Bristol Royal Infirmary Inquiry. The inquiry into the management of children receiving complex heart surgery at the Bristol Royal Infirmary. London: The Stationery Office Limited, 2001.

6. The Royal Liverpool Children's inquiry. The Report of the Royal Liverpool Children's inquiry. London: HMSO, 2001.

7. Department of Health. Reference guide to consent for examination or treatment. London: Department of Health, 2001. http://www.dh.gov.uk/assetRoot/04/01/90/79/04019079.pdf

8. Chadha N K, Repanos C. How much do healthcare professionals know about informed consent? A Bristol experience. Surgeon 2004; 360: 328-333.

9. Ibrahim T, Ong S M, Taylor G J. The new consent form: is it any better? Ann R Coll Surg Eng/ 2004; 86: 206-209.

10. Byrne D J, Napier A, Cuschieri A. How informed is signed consent? Br Med J 1988; 296: 839-840.

11. Chatterton v Gerson 1981. 1 All ER 257, 265 per Bristow J.

12. Askew G, Pearson K W, Cryer D. Informed consent: can we educate patients? $J$ R Coll Surg Edinb 1990; 35: 308-309.

13. Langdon I J, Hardin R, Learmoth I D. Informed consent for total hip arthroplasty: does a written information sheet improve recall by patients? Ann $R$ Coll Surg Engl 2002; 84: 404-408.

14. Dobree L. Pre-admission booklets for patients awaiting surgery. Nursing Times 1989; 85: 42-44

15. Mortensen M G, Kiyak H A, Omnell L. Patient and parent understanding of informed consent in orthodontics. Am J Orthod Dentofacial Orthop 2003; 124: 541-550.

16. Lo W, Yap W L. Audit of consent for orthodontic treatment. British Orthodontic Society Clinical Effectiveness Bulletin 2004; 17, 3.

17. Pearce vs United Bristol Healthcare NHS Trust. [1998] 48BMLR (CA).

18. Haines W F, Williams D W. Consent and orthodontic treatment. Br J Orthod 1995; 22: 101-105.

19. Bolam v Friern. Hospital Management Committee [1957] 2 AllER 118, 1 WLR 582

20. Gorelick L, Geiger A M, Gwinnett A J. Incidence of white spot formation after bonding and banding. Am J Orthod 1982; 81: 93-98.

21. Mirabella A D, Artun J. Prevelance and severity of apical root resorption of maxillary anterior teeth in adult orthodontic patients. Eur J Orthod 1995; 17: 93-97.

22. Pratelli $P$, Gelbier S, Gibbons D E. Lack of knowledge among parents, of the implications of receiving orthodontic treatment. Community Dent Health 1996; 13: $211-214$ 
23. Wu W C, Pearlman R A. Consent in medical decision making. J Gen Int Med 1988; 3: $9-14$.

24. House of Lords Judgements - Chester vs Afshar. [2004] UKHL 41. http://www. publications.parliament.uk/pa/ld200304/ldjudgmt/jd041014/cheste-1.htm

25. Sims A P, Roberts-Harry T J, Roberts-Harry D P. The incidence and prevention of ocular injuries in orthodontic practice. Br J Orthod 1993; 20: 339-343.
26. Jackson $C$, Lindsay S. Reducing anxiety in new dental patients by means of leaflets. Br Dent J 1995; 179: 163-167.

27. Makdessian A S, Ellis D A, Irish J C. Informed consent in facial plastic surgery: effectiveness of a simple educational intervention. Arch Facial Plast Surg 2004; 6: 26-30.

28. Gauld V A. Compliance and recall. J R Coll Gen Pract 1981; 83: 298-300. 